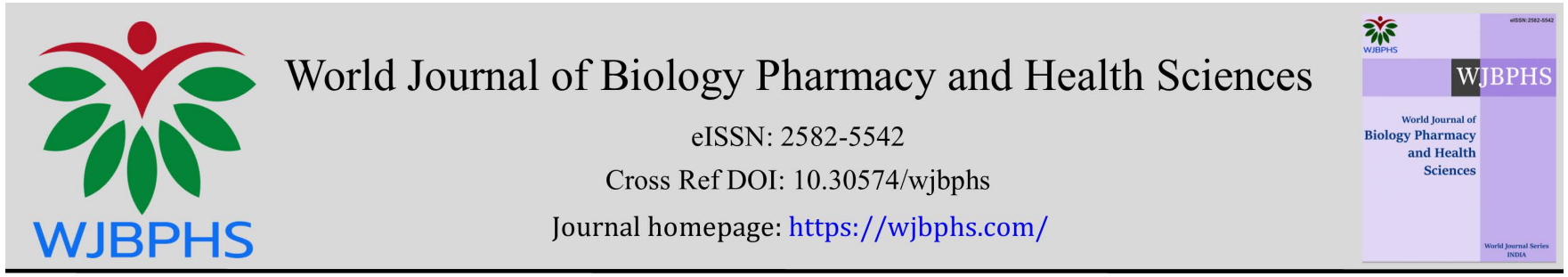

(REVIEW ARTICLE)

\title{
The anxiolytic effect of some plant extracts in clinical trials and animal models
}

\author{
Malkhaz Makashvili 1, ${ }^{*}$, Giorgi Andronikashvili 2, Tamila Bagashvili 2, Tea Gurashvili ${ }^{2}$, Ketevan Gogeshvili ${ }^{2}$, \\ Tamar Nadiradze ${ }^{3}$ and Nino Akhobadze 2 \\ ${ }^{1}$ Faculty of Psychology, Ilia State University, Tbilisi, Georgia. \\ ${ }^{2}$ Department of Experimental Neurology, Ivane Beritashvili Center of Experimental Biomedicine, Tbilisi, Georgia. \\ ${ }^{3}$ Department of Science and Digital Technology, I.Gogebashvili University, Telavi, Georgia.
}

World Journal of Biology Pharmacy and Health Sciences, 2021, 05(03), 038-043

Publication history: Received on 02 February 2021; revised on 03 March 2021; accepted on 05 March 2021

Article DOI: https://doi.org/10.30574/wjbphs.2021.5.3.0023

\begin{abstract}
The phenomenon of anxiety remains poorly understood and there is much to be learnt about its's effective treatment. Here we discuss the data of available scientific literature concerning the use of plant derived extracts in the treatment of anxiety. Study of the treating effects of natural alternatives to prescription drugs is very important in regard to limitations of current drug therapies. Significance of the study of treating efficacy of endemic plant species, endemic to Georgia in particular, and the use of animal models, such as rat grooming and rat behavior in maze, for evaluation of the anxiolytic efficacy of phytomedicines is discussed as well. We conclude, that medical as well as experimental trials in animal models of anxiety provide strong argument for the use of plant extracts as an alternative to the current drug therapies for anxiety.
\end{abstract}

Keywords: Anxiety; Treatment; Plant extracts; Animal models

\section{Introduction}

Stress-induced anxiety, as a consequence of the impact of stressogenic environment on living things, remains poorly understood and there is much to be learnt about its's effective treatment. Nowadays, treatment of anxiety gets special significance with respect to the negative influence of COVID pandemic on the emotional status of people [1]. Antidepressant and anxiolytic drugs are most commonly prescribed in order to treat anxiety. However current drug therapies have limitations such as high financial expense and side effects [2-4] as well as drug dependence and stigma associated with consuming and depending on pharmaceuticals $[5,6]$. Therefore, further research is necessary to find new anxiolytics with less adverse effects and higher availability for wider community [7]. Herbal alternatives are distinguished with their lower costs and consequent availability for wider community as compared to drugs, produced by pharmaceutical industry. Many of these natural alternatives are available in some form at local pharmacies, or are easily obtainable from online websites, making them more accessible than prescription drugs. According to World Health Organization, about three-quarters of the world population relies upon traditional remedies for the health care [8].

Natural alternatives are derived from plants and have demonstrated anxiolytic effects in both humans and animals. They have been used as traditional food and medicines for a range of illnesses for centuries [9]. A systematic review of the published literature revealed trial data for several plant species (Ginkgo biloba, Lavandula angustifolia, Hypericum perforatum, Valeriana officinalis, Crataegus oxyacantha and Eschscholzia californica as well as Matricaria recutita, Melissa officinalis, Passiflora incarnate and Piper methysticum) demonstrating high level of evidence for the treatment of anxiety disorders [10]. Several human clinical trials provide preliminary positive evidence of anxiolytic activity of

\footnotetext{
${ }^{*}$ Corresponding author: Malkhaz Makashvili

Ilia State Univerity, Tbilisi, Georgia.
}

Copyright $(2021$ Author(s) retain the copyright of this article. This article is published under the terms of the Creative Commons Attribution Liscense 4.0. 
extracts of Matricaria recutita, Ginkgo biloba, Passiflora incanata, Echium. amoenum and Scutellaria lateriflora [9]. Other systematic reviews of the anxiolytic effect of essential oils in translational medicine models suggest the extracts of plant species Achillea wilhemsii, Angelica sinensis, Alpiniazerumbet, Celastarus paniculatus, Chamaecyparis obtuse and Citrus aurantium subsp. bergamia, as well as Citrus janus, Citrus latifolia, Citrus reticulate, Citrus sinensis, Cymbopogon citratus and Copaifera reticulate, Ducrosia anethifolia, Foeniculum vulgare, Lavendula angustifolia, Lippia alba, Spiranthera odoratissima and Stachys tibetica to exert anxiolytic effect [11]. Salix aegyptiaca is shown to decrease the anxiety in animals as well [12]. Various plant species have been used from immemorial in Asia by local tribes as food and medicine [13]. The search for endemic plants species, as a candidates for medicinal use, has special importance with this respect. Endemism is the ecological state of a species being unique to a defined geographic location, such as an island, nation, country or other defined zone, or habitat type. Factors, specific to their location, such as microclimate, determine anatomical and physiological characteristics of endemic species. Endemism influences the chemical content (phytochemicals) of the plant species and this makes endemic plants the focus of interest for their use in medicine [14$16]$.

Endemic plant species of Georgia does not make exclusion with this respect. Various plants have been used as a source of herbal medicines for centuries and investigation of Georgian medicinal manuscripts of X-XVIII centuries confirmed the use of various plant species for medical purposes [17,18]. Earlier, in unpublished study, we collected information on some plant species, endemic to Georgia (Galanthus lagodechianus Kem-Nath., Campanulla kachetica Kantsch., Gypsophila steveni Fisch. \& Schranl and Gymnospermium smirnowii (Trautv)Takht.) from local dwellers in the territory of the spread of these endemic species. Respondents were questioned concerning the use of the plant species as a phytomedicines. Respondents witnessed the use of extracts of the plant species of interest in combination with other plant extracts as sedatives. At the same time, respondents provided information about anatomical parts (roots, leaves etc.), usable for medicinal purposes, the period (season) when species should be collected and what is a method of preparation of the herbal medicine. Further research is necessary, however, to get scientifically relevant data confirming the medical effects of these endemic plants, and their anxiolytic capacity in particular.

Usually, the treating capacity of plant derived phytochemicals is studied on animal models. For example, Zebra fish animal model is used in research of traditional Chinese medicines [19]. Here we concentrate on two models - rat grooming and rat behavior in elevated maze.

Rat grooming as well as rat behavior in Elevated Plus-Maze (EPM) are good candidates for studying the effect of plant derived medicines on anxiety. Both, grooming as well as behavior in EPM belong to the ethologically based animal models of fear and anxiety. Models of this kind attempt to approximate the natural conditions under which such emotional states are elicited. By employing nonpainful aversive stimuli to induce fear and anxiety, ethological tests minimize possible confounding effects of motivational or perceptual states arising from interference with learning/memory, basic physiological needs or pain-inducing mechanisms. In comparison to conditioned models, ethologically based tests are suggested better analogs of human anxiety [20].

Behavior, expressed in strokes, licks and scratching of entire body is known as "Grooming". Grooming is an innate behavior which may be expressed as either self-grooming or allogrooming - care of conspecific's body [21-26] and is represented across species of mammals and birds, as well as in some representatives of insects [22]. Grooming plays an important role in the care of body surface and regulation of body temperature, as well as in social communication among conspecifics $[22,26]$. At the same time, grooming lowers the level of anxiety and helps in adaptation to stressogenic environment [27-29]. Rodents are distinguished by rich grooming repertoire and for this reason scientists focus on grooming in laboratory rats [30].

Grooming in rats consists of two principal patterns such as syntactic chain embedded in other forms of grooming behavior. Syntactic chain represents grooming movements into distinct, predictable phases that follow the cephaliccaudal direction, starting from the head and ending in genitals and the tail. The phases of syntactic chain are such as 1 . licking the paws, 2. nose and face grooming (strokes along the snout), 3. head washing (strokes over the top of the head and behind the ears by the forepaws), 4. scratching body by hind paws and licking the body fur and 5. licking hind paws, tail and genitals. Some authors distinguish 3 phases such as rostral grooming (grooming of forepaws, nose and face), head washing and body grooming - grooming of body, hind paws and tail/genitals [23].

Natural grooming develops spontaneously and may be observed in everyday situation, while in the experiment grooming may be provoked by various stressors. Stressors used for experimental provocation of grooming behavior are such as handling by the tail, restraints, placement of the animal in novel chamber, fur moistening, delivering noise, exposition to the bright light, predator or larger conspecific. 
Grooming behavioral microstructure undergoes predictable changes in stressful situations [21,24]. Increase in the percentage of interrupted grooming bouts, incorrect transitions from one grooming phase to another as well as more rostral pattern of grooming is described as a reaction to the stressor. These changes in grooming microstructure are believed a behavioral marker of stress in rats [29]. At the same time, the change in grooming microstructure depends on the strength of stressor. For example, fur moistening, as a stressor affects grooming much less as compared to the exposition to the bright light [30-32], the data confirming the earlier reports of other authors [33] and in accordance to the more recent reports [34-36]. Therefore, the change in the grooming pattern may identify the stress in the rats and at the same time, may serve as a measure of the strength of stress-induced disorders.

Stress-induced grooming was found to significantly decrease in rats, treated with Citrus bergamia essential oil as compared to the control non-treated animals [37]. The same anxiolytic effect was confirmed for aqueous extract of Alafia multiflora stem barks in rodents [38]. Significant decrease in grooming activity in Open Field Test was registered in rats, treated with Arnica montana [39], Cinnamomum tamala and Withania somnifera extracts [40]. We reported on anxiolytic effect of the tincture of Melissa officinalis in rats, exposed to the bright light as compared to the control group, not treated with the tincture [41].

EPM method relies upon rodents' unconditioned fear of heights/open spaces (avoidance). Behavioral responses in the EPM are easily assessed and quantified by an observer. Briefly, rodents are placed in the intersection of the four arms of the EPM and their behavior is typically recorded for $5 \mathrm{~min}$. The behaviors that are typically recorded when rodents are in the EPM are the time spent and entries made on the open and closed arms. Behavior in this task (i.e., activity in the open arms) reflects a conflict between the rodent's preference for protected areas (e.g., closed arms) and their innate motivation to explore novel environments. Anti-anxiety behavior (increased open arm time and/or open arm entries) is determined simultaneously with a measure of spontaneous motor activity (total and/or closed arm entries). An increase of the time and the proportion of the entrances into the open arms without a changed locomotor activity are regarded as a powerful marker for an anxiolytic substance effect. Other ethological measures that can be observed in rodents in the maze are the number of rears, head dips, fecal boli, freezing or stretched-attend postures [42-44].

The per or administration of Mercurialis annua extract showed an anxiolytic effect by increasing the time spent on open arms and the percentage of open arm entries compared to the control group [45,46]. Aqueous extract of leaves of Coriandrum sativum is shown to possess dose-depended anxiolytic activity [47]. Aqueous extract of Urtica urens is suggested to increase the time spent on open arms and the percentage of open arm entries in plus maze as compared to control group. Treatments of experimental rats with the aqueous/alcoholic extract of Plectranthus amboinicus significantly increased the time-spent and entries into open arms of the EPM, and reduced the time-spent and entries into the closed arms versus saline controls [48]. Significant anxiolytic effects of Lagenaria cineraria extracts in rats was demonstrated in EPM [49]. Allium jesdianum extract increased time spent and the number of entrance in the open areas of EPM [50]. Treatment with the extract of Ficus sycomorus reduced the time and the number of entries into the closed arms of plus maze in rats [51]. The per or administration of the extract of ethanolic extract of Indian Abies pindrow leaf showed significant anxiolytic effects on all the paradigms of anxiety, reflected in the significant increase in open field ambulation and slight increase in rearing and activity in the center [52]. Rats treated with the extract of Melissa officinalis displayed high percentage of open-arm entries in the EPM as compared to the control non-treated animals [53].

\section{Conclusion}

The anxiolytic effects of several phytomedicines is demonstrated in medical trials as well as in experimental trials in animal models of anxiety. Taken together, these data are convincing, that plant extracts are efficient in the treatment of anxiety and plant-derived medicines may be considered an alternative to the prescription drug therapies for anxiety. This knowledge is beneficial for society, as long as herbal alternatives to prescription drugs are distinguished with less side effects as well as lower costs and consequent availability for wider community.

\section{Compliance with ethical standards}

\section{Acknowledgement}

Authors express their special thanks of gratitude to professor Manana Khutsishvili for help in determination of botanical names of plant species endemic to Georgia.

\section{Disclosure of conflict of interest}


There is no conflict of interests to declare.

\section{Statement of ethical approval}

The content of the manuscript is approved by the Ethic Committee of the Ivane Beritashvili Center of Experimental Biomedicine, Tbilisi, Georgia.

\section{References}

[1] Salari N, Hosseinian-Far A, Jalali R, Vaisi-Raygani A, Rasoulpoor S, Mohammadi M,et al. Prevalence of stress, anxiety, depression among the general population during the COVID-19 pandemic: a systematic review and metaanalysis. Global Health. 2020; 16(57): 1-11.

[2] Rahmati B, Kiasalari Z, Roghani M, Khalili M, Ansari F. Antidepressant and anxiolytic activity of Lavandula officinalis aerial parts hydro alcoholic extract in scopolamine-treated rats. Pharmaceutical biology. 2017; 55(1): 958-65.

[3] Rothschild AJ. Sexual side effects of antidepressants. J Clin Psychiatry. 2000; 47: 28-36.

[4] Masand PS, Gupta S. Long-term side effects of newer generation antidepressants: SSRIS, venlafaxine, nefazodone, bupropion, and mirtazapine. Ann Clin Psychiatry. 2002; 14: 175-82.

[5] Davidson JR, Feltner DE, Dugar A. Management of generalized anxiety disorder in primary care: identifying the challenges and unmet needs. Prim Care Companion J Clin Psychiatry. 2010; 12(2): PCC.09r00772.

[6] Huffman JC, Alpert JE. An approach to the psychopharmacologic care of patients: antidepressants, antipsychotics, anxiolytics, mood stabilizers, and natural remedies. Med Clin North Am. 2010; 94: 1141-60.

[7] Sahoo S, Brijesh SD. Pharmacogenomic assessment of herbal drugs in affective disorders, Biomedicine \& Pharmacotherapy. 2019; 109: 1148-62.

[8] Gilani AH, Rahman AU. Trends in ethnopharmocology. J Ethnopharmacol. 2005; 22: 43-9.

[9] Sarris J, Panossian A, Schweitzer I, Stough C, Scholey A. Herbal medicine for depression, anxiety and insomnia: A review of psychopharmacology and clinical evidence, Eur. Neuropsychopharmacol. 2011; 21(12): 821-60.

[10] Ernst E. Herbal remedies for depression and anxiety. Advances in Psychiatric Treatment. 2007; 13: 312-6.

[11] De Sousa, DP, de Almeida Soares Hocayen P, Andrade LN, Andreatini R. A Systematic review of the anxiolytic-like effects of essential oils in animal models. Molecules. 2015; 20(10): 18620 - 60.

[12] Komaki A, Hashemi-Firouzi N, Kakaei S, Shahidi S, Sarihi A, Salehi I. Investigating the effect of hydro-alcoholic extract of Salix aegyptiaca on anxiety in male rat. Adv Biomed Res. 2015; 4: 258.

[13] Ganguli S. Herbal immune enhancers abd indigenous herbs, plants and fruits and its traditional implications in therapy including alternative medicines. In: (Ganguli S.), Herbal immune enhancers abd indigenous herbs, plants and fruits and its traditional implications in therapy including alternative medicines Science and education development Institute, Nigeria. 2014.

[14] So GO, Li HT, Sun H, Zhang XB, Zhang LX, Li YJ, Huang LQ, Ma XG. Endemic plants for medicine use in China, Zhongguo Zhong Yao Za Zhi. 2017; 42(22): 4329-35.

[15] Govea-Salas M, Morlett-Chávez J, Rodriguez-Herrera R, Ascacio-Valdés J. Some Mexican plants used in traditional medicine,. In: (Hany A. El-Shemy), Aromatic and medicinal Plants - Back to Nature. IntechOpen.2017.

[16] Rummun N, Neergheen-Bhujun VS, Pynee KB, Baider C, Bahorun T. The role of endemic plants in Mauritian traditional medicine - Potential therapeutic benefits or placebo effect? J Ethnopharmacol. 2018; 1(213): 111-117.

[17] Shengelia R. Study of the history of medicine in Georgia. Croat Med J. 1999; 40(1): 38-41.

[18] Shengelia R, Khelaia N, Chkhaidze Z, Gurgenidze M, Mamatsashvili T. Aspects of aging in Georgian traditional medicine. Georgian Med News. 2005; 129: 123-7.

[19] Wang D, Hu Guojun, Wang J, et al. Studying CNS effects of traditional Chinese medicine using zebrafish models. Journal of ethnopharmacology. 2021.

[20] Bourin M. Animal models for screening anxiolytic-like drugs: a perspective. Dialogues in clinical neuroscience. 2015; 17(3): 295-303. 
[21] Kalueff AV. Grooming and Stress. Complement Med Ther. 2020; 20(1): 149-52.

[22] Kalueff AV, Laporte JL, Bergner CL. Neurobiology of grooming behavior. Cambridge Univ. In: (Kalueff AV, La Porte JL, Bergner C), Neurobiology of Grooming Behavior. Cambridge Univ. Press. 2010.

[23] Kalueff AV, Stewart AM, Song C, Berridge KC, Graybiel AM, Fentress JC. Neurobiology of rodent self-grooming and its value for translational neuroscience. Nat Rev Neurosci. 2016; 17(1): 45-59.

[24] Komorowska J, Pellis SM. Regulatory mechanisms underlying novelty-induced grooming in the laboratory rat. Behav Process. 2004; 67: 287-93.

[25] Spruijt BM., van Hoof I, Gispen WH. Ethology and neurobiology of grooming behavior. Physiological reviews. 1992; 72(3): 825-52.

[26] Thiessen DD. Body temperature and grooming in the Mongolian gerbil. Annals of the New York Academy of Science. 1988; 525: 27-39.

[27] Stilwell FM, Fentress JC. Grooming, sequences and beyond. 1-19. In: Neurobiology of grooming behavior. Cambridge Univ. In: (Kalueff AV, La Porte JL, Bergner C), Neurobiology of Grooming Behavior. Cambridge Univ. Press. 2010.

[28] Pellis SM, Pellis VC. Social play, social grooming and the regulation of social relationships. 66-88. In: Neurobiology of grooming behavior. Cambridge Univ. In: (Kalueff AV, La Porte JL, Bergner C), Neurobiology of Grooming Behavior. Cambridge Univ. Press. 2010.

[29] Beery AK, Kaufer D. Stress, social behavior and resilience: Insights from rodents. Neurobiology of stress. 2015; 1: 116-27.

[30] Kalueff AV, Stewart AM, Dong C, Berrige KC, Graybel AM, Fentress JC. Neurobiology of rodent self-grooming and its value for translational science. Nature Reviews Neuroscience. 2016; 17(1): 45-59.

[31] Makashvili M, Bagashvili T, Andronikashvili G, Gurashvili T, Gogeshvili K, Akhobadze N. et al. Grooming, rearing and stretch-attend posture in response to fur moistening in Albino Mongrel Rat. in: (Mitagvaria N.), Nova Science Publishers, New York. 2018.

[32] Makashvili M, Bagashvili T, Andronikashvili G, Gurashvili T, Gogeshvili K, Akhobadze N. Is fur moistening relevant approach to the study of rat grooming in response to stress? Mat. 4th Multidisciplinary Conference on Rheology. 2018; 44-5.

[33] Kalueff AV, Tuohimaa P. The grooming analysis algorithm discriminates between different levels of anxiety in rats: potential utility for neurobehavioral stress research. J of Neuroscience Methods. 2005; 143: 169-77.

[34] Estanislau C. Cues to the usefulness of grooming behavior in the evaluation of anxiety in the EPM. Psychology and Neuroscience. 2012; 5 (1): 105-12.

[35] Smolinsky AN, Bergner CL, LaPort, J, Kalueff AV. Analysis of grooming behavior and its study utility in studying animal stress, anxiety and depression. In: (Gould TD), Mood and anxiety related phenotypes in mice. Neuromethods, 42, Humana Press. 2009.

[36] Wilson NV, Filgueiras, GB, Lorenzo P, Estanislau C. Modulation of Grooming Behavior. in: Rats by different test situations, Psychology \& Neuroscience (C) 2016, American Psychological Association. 2016.

[37] Rombolà L, Scuteri D, Adornetto A, Straface M, Sakurada T, Sakurada Sh, Mizoguchi H, et al. Anxiolytic-like ffects of bergamot essential oil Are Insensitive to flumazenil in rats. Evidence-based complementary and alternative medicine. 2019.

[38] Foyet HS, Tsala DE, Boub, AA, Hritc, L. Anxiolytic and antidepressant-like effects of the aqueous extract of Alafia multiflora stem barks in rodents. Advances in pharmacological sciences. 2012; 912041.

[39] Jha P, Bhalerao S, Dhole M. Analysis of anxiolytic actiovity of Arnica monatana and alprazolam in rats using open field test. Internat J basic Clin Pharmacol. 2018; 7(4): 718-22.

[40] Upadhyay G, Khoshla S, Kosuru R, Singh S. Anxiolytic, antidepressant, and antistress activities of the aqueous extract of Cinnamomum tamala Nees and Eberm in rats. Indian J Pharmacol. 2016; 48: 555-61.

[41] Makashvili M, Bagashvili T, Andronikashvili G, Gurashvili T, Gogeshvili K, Akhobadze N. et al. The effect of the tincture of Melissa officinalis L. on rat grooming in response to stressor. Mat. International multidisciplinary conference on biomedicine - Biomed-2019. 2019; 45-46. 
[42] Lister RG. The use of a plus-maze to measure anxiety in the mouse. Psychopharmacol. 1987; 92: 180-5.

[43] Carobrez AP, Bertoglio LJ. Ethological and temporal analyses of anxiety like behavior: The EPM model 20 years on. Neurosci Biobehav Rev. 2005; 29: 1193-1205.

[44] Walf AA, Frye CA. The use of the EPM as an assay of anxiety-related behavior in rodents. Nat Protoc. 2007; 2 (2): 322-8.

[45] Doukkali Z, Bouidida H, Srifi A, et al. Anxiolytic plants in Morocco: Ethnobotanical and ethno-pharmacological study. Phytothérapie. 2014; 306-13.

[46] Doukkali Z, Kamal R, El Jemeli M, Nadjmouddine M, Amina Zellou M, Cherrah Y et al. Anti-anxiety effects of Mercurialis annua aqueous extract in the EPM Test. Pharmaceutical Bioprocessing. 2016; 4(4): 56-61.

[47] Latha K, Rammohan B, Sunanda BP, Maheswar, M, Mohan SK. Evaluation of anxiolytic activity of aqueous extract of Coriandrum sativum Linn. in mice: A preliminary experimental study. Pharmacognosy research. 2015; 7 (Suppl 1): S47-S51.

[48] Tiwari DK, Hemant NH, Gaurav G, Tripathy RK, Jena J. Evaluation of anti-anxiety activity of Plectranthus amboinicus (Lour.) on rats. Asian J Pharm Clin Res. 2012; 5(4): 110-3.

[49] Shuyuan Wang, Shujing Wu, Souravh Bais, Ruihua Hou. Ameliorative. Potential of Lagenaria sicereria extract as anti-anxiety drug in various models of anxiety in rats. Internat J of Pharmacol. 2018; 14: 1179-87.

[50] Mousavi R, Fashi ZH, Jahromy MH, Rasooli R. Potential of the Allium jesdianum Extract in suppression of anxiety and depression in mice. Br Biomed Bull. 2017; 5: 302.

[51] Foyet HS, Tchinda Deffo S, Koagne Yewo P et al. Ficus sycomorus extract reversed behavioral impairment and brain oxidative stress induced by unpredictable chronic mild stress in rats. BMC Complement Altern Med. 2017; 17: 502 .

[52] Kumar V, Singh RK, Jaiswal AK, Bhattacharya SK, Acharya SB. Anxiolytic activity of Indian Abies pindrow Royle leaves in rodents: an experimental study. Indian J Exp Biol. 2000; 38(1): 36-41.

[53] Adefunmilayo E, Taiwo FB, Lweite G, Fereira VM. Anxiolytic and antidepressant-like effects of Melissa officinalis (Lemon balm) extract in rats: Influence of administration and gender. Indian J Pharmacol. 2012; 44 (2): 189-92. 